\title{
VARIABILIDADE DE NUTRIENTES EM PLANTAS DE MILHO CULTIVADO EM TALHÃO MANEJADO HOMOGENEAMENTE ( $\left.{ }^{1}\right)$
}

\author{
ZAQUEU FERNANDO MONTEZANO $\left({ }^{2}\right)$; EDEMAR JOAQUIM CORAZZA $\left({ }^{3}\right)$; TAKASHI MURAOKA $\left({ }^{4}\right)$
}

\begin{abstract}
RESUMO
O conhecimento da variabilidade da nutrição de plantas e da produtividade em áreas cultivadas pode fornecer importantes subsídios na racionalização do uso de insumos e auxiliar no manejo da fertilidade do solo. O objetivo deste trabalho foi avaliar a variabilidade da nutrição mineral de plantas de milho por meio do fracionamento de um talhão cultivado comercialmente em células de manejo e verificar as relações com a produtividade. O estudo foi realizado na Fazenda Alto Alegre, em Planaltina (GO), em área de 373 hectares de Latossolo Vermelho-Amarelo Distroférrico, cultivado com milho na safra 2003/04. Traçado um polígono da área, procedeu-se sua divisão em 80 células de manejo de quatro hectares cada uma. A amostragem de folhas em cada célula seguiu uma diagonal com 12 pontos para compor uma amostra composta. Realizou-se a análise dos macro e micronutrientes nas folhas. A produtividade para cada célula foi obtida por meio de colhedora equipada com GPS. Na análise da variabilidade dos resultados foram considerados os parâmetros estatísticos descritivos. O teste ausência de correlação foi realizado com o nível de significância de 5\%. A variabilidade da concentração dos nutrientes na folha indicadora do milho foi considerada baixa para N, P, K, S e Mg; e média para Ca, Cu, $\mathrm{Fe}, \mathrm{Mn}$ e Zn. A variabilidade da produtividade de milho revelou diferenças de produção para cada célula analisada. Os coeficientes de correlação entre os nutrientes e a produtividade foram significativamente diferentes de zero $(\mathrm{p}<0,05)$ e negativos para $\mathrm{Cu}$, Mn e $\mathrm{Zn}$.
\end{abstract}

Palavras-chave: Zea mays, nutrição mineral, escala de campo, plantio direto, Latossolo, Cerrado.

\section{ABSTRACT \\ CORN PLANT NUTRIENT VARIABILITY IN AN HOMOGENEOUSLY MANAGED CROP FIELD}

The knowledge of variability of plant nutrition and grain productivity in cultivated areas may provide important information for rational use of fertilizers and soil amendments. The objective of this case study was to determine the corn plant mineral nutrition variability through the fractionation of a commercial grown corn field into small management cells. The study was carried out at the farm Alto Alegre in Planaltina, Goiás State, Brazil, on a Typic Dystrarox soil in 373 ha area of corn crop during the crop year of 2003/2004. After outlining a polygon of area it was divided into 80 management cells of 4 ha each. The leaf sampling followed a diagonal with twelve points to constitute a representative composite sample within each cell. The leaf samples were analyzed for macro and micronutrients. Yield for each cell was obtained through grain yield monitor of a combine harvester equipped with GPS. For data variability analysis descriptive statistic parameters were considered. Test for correlation coefficients were accomplished considering the significance level of $5 \%$. The variability of nutrient content in the diagnostic leaves were considered low for N, P, K, S and Mg content; and medium for $\mathrm{Ca}, \mathrm{Cu}, \mathrm{Fe}, \mathrm{Mn}$ e Zn. Yield variability showed yield differences among cells. Linear correlation coefficients between nutrient content and grain yield were significant and negative for $\mathrm{Cu}, \mathrm{Mn}$ and $\mathrm{Zn}$.

Key words: Zea mays, mineral nutrition, field-scale, no-till, Oxisol, Cerrado.

$\left({ }^{1}\right)$ Parte da dissertação de mestrado do primeiro autor. Recebido para publicação em 8 de junho de 2005 e aceito em 18 de julho de 2008.

$\left(^{2}\right)$ Doutorando em Solos e Nutrição de Plantas pela ESALQ/USP, Laboratório Fertilidade do Solo, CENA/USP. E-mail: zaqueu@esalq.usp.br ( $\left.{ }^{*}\right)$ Autor correspondente. Bolsista CNPq.

$\left(^{3}\right)$ Embrapa Informação Tecnológica - PqEB, Caixa Postal 040315, 70770-901 Brasília (DF). E-mail: edemar@sct.embrapa.br

$\left({ }^{4}\right)$ Centro de Energia Nuclear na Agricultura - CENA/USP. E-mail: muraoka@cena.usp.br 


\section{INTRODUÇÃO}

A área plantada e a produtividade da cultura do milho para grãos vêm aumentando paulatinamente nas últimas décadas, e a cultura tem papel importante no agronegócio brasileiro, que passou de um país importador para exportador. Nesse contexto, por conseqüência do melhoramento genético realizado ao longo dos anos para obter alto potencial produtivo, a planta tornou-se mais exigente em nutrientes.

Uma das formas de se aumentar a produtividade da cultura é, sem dúvida, a nutrição mineral adequada, por meio de programas de adubação que considerem, além da quantidade de fertilizantes fornecida, o balanço entre os nutrientes requeridos, aliado a condições climáticas adequadas, principalmente a precipitação pluvial (BÜLL, 1993).

A utilização da análise foliar como critério diagnóstico baseia-se na premissa da existência de relação significativa entre o suprimento de nutrientes e os teores dos elementos na folha, e que aumentos ou decréscimos nas concentrações se relacionam com produções maiores ou menores respectivamente (Malavolta et al., 1997).

Em estudo com a variabilidade de fósforo na planta e no solo, CAMELO et al. (1993/94) concluíram que a intensidade de amostragem poderia ser menor para o fósforo na planta do que no solo. Considerando que o número mínimo de subamostras de solo é diretamente proporcional ao coeficiente de variação, quanto maior o coeficiente de variação, maior será o número de subamostras a serem coletadas (SILVEIRA et al., 2000). Isto se aplica também quando se pretende definir o número de subamostras para determinar atributos de nutrição mineral de plantas.

Segundo Salviano et al. (1998), os coeficientes de assimetria e de curtose dos atributos são apresentados para efeito de comparação com a distribuição normal, para a qual estes coeficientes são, respectivamente, zero e três. Esses autores verificaram que os atributos matéria seca e altura de plantas de crotalária tiveram coeficientes de assimetria e curtose que se aproximam ao de uma distribuição normal, diferentemente para a maioria dos atributos químicos do solo. Segundo os mesmos autores, essa distribuição corrobora o baixo coeficiente de variação dos atributos relacionados a planta em comparação aos atributos do solo.

Considerando a classificação proposta por WarRick e Nielsen (1980) para os atributos físicos do solo, aqueles com coeficientes de variação acima de $12 \%$ e abaixo de $52 \%$ foram classificados como de média variabilidade, sendo os atributos com coeficiente de variação abaixo e acima deste intervalo classificados, respectivamente, como de baixa e alta variabilidade.

Em diversos trabalhos tem sido comentado que a planta atua como integradora da variabilidade do solo (Trangmar et al., 1987; Souza, 1992; Camelo et al., 1993; 1994; SALVIANo et al., 1998), ou seja, como a planta explora um volume de solo maior do que o representado por uma amostra, ela pode então diluir a variabilidade edáfica, compensando diferenças pontuais no solo (CAMELo et al., 1993; 1994). Para Souza (1992), a extensão do sistema radicular a curta distância pode constituir fator de ajustamento da planta às variáveis do solo. Para as gramíneas, isso seria mais preponderante do que para uma espécie vegetal com sistema radicular pivotante, que pode explorar camadas mais profundas do solo e, conseqüentemente, sua heterogeneidade.

O conhecimento da variabilidade das concentrações de nutrientes em plantas de milho e da correlação com a produtividade em áreas consideradas e manejadas homogeneamente é fundamental para diagnosticar possíveis carências ou excessos de nutrientes na cultura, seja em locais específicos, seja em área total. Este diagnóstico permite uma avaliação da resposta da cultura às fertilizações realizadas e ao histórico de manejo da área considerada, além de esclarecer possíveis problemas ocasionados por diferentes fatores que influenciam na produtividade. A diagnose foliar pode ser considerada uma ferramenta complementar na interpretação dos dados de análise de solo.

Este trabalho teve por objetivo avaliar a variabilidade das concentrações de nutrientes de plantas de milho determinadas por meio da análise foliar num talhão manejado homogeneamente e verificar possíveis relações com a produtividade da cultura do milho.

\section{MATERIAL E MÉTODOS}

O estudo de caso foi desenvolvido na Fazenda Alto Alegre, localizada no município de Planaltina (GO), em área de 373 hectares. O solo da área, segundo Embrapa (1999), é classificado como Latossolo Vermelho-Amarelo Distroférrico. De 1987 a 1989, a área que estava sob vegetação natural de Cerrado foi desmatada para o cultivo da soja. Após 1994, a área passou a ser cultivada em semeadura direta com a utilização do milho, além da soja.

A dessecação da área foi realizada no período de $31 / 10$ a 5/11/2003 com 2,75 $\mathrm{L} \mathrm{ha}^{-1}$ de glifosato + 0,6 L ha ${ }^{-1}$ de 2,4-D amina. No período de $3 / 11$ a 10/ 
$11 / 2003$, realizou-se a semeadura direta com os híbridos 30F90, 30K75 e 3021 da Pioneerâ, com 64.000 sementes por hectare para obter uma população final de aproximadamente 60.000 plantas. As sementes foram tratadas com o inseticida à base de tiodicarbe. Efetuou-se o controle de invasoras com aplicações em pré-emergência do milho do herbicida atrazina + simazina, no período de $3 / 11$ a 8/11/2003. Aplicaramse, no plantio, 25, 90 e $50 \mathrm{~kg} \mathrm{ha}^{-1}$ de N, $\mathrm{P}_{2} \mathrm{O}_{5}$ e $\mathrm{K}_{2} \mathrm{O}+$ $\left(4,5 ; 2,5 ; 0,30 ; 0,08 ; 0,08 ; 0,15 \mathrm{~g} \mathrm{~kg}^{-1} \mathrm{de} \mathrm{Ca}, \mathrm{S}, \mathrm{Zn}, \mathrm{B}, \mathrm{Cu}\right.$ e Mn respectivamente). A primeira adubação em cobertura, no período de 18/11 a 1. $/ 12 / 2003$, foi feita com 35 e $30 \mathrm{~kg} \mathrm{ha}^{-1}$ de $\mathrm{N}$ e $\mathrm{K}_{2} \mathrm{O}$, respectivamente, na forma de nitrato de amônio e cloreto de potássio, distribuídos a lanço. A segunda, no período de 26/11 a 15/12/2003, foi efetuada na dose de 45 e $20 \mathrm{~kg} \mathrm{ha}^{-1}$ de $\mathrm{N}$ e $\mathrm{K}_{2} \mathrm{O}$, respectivamente, como uréia e cloreto de potássio, incorporados nas entrelinhas. Realizou-se uma aplicação de inseticida fisiológico nuvaluron para o controle da lagarta do cartucho em área total no período de 11/12 a 30/12/2003.

A definição dos pontos e procedimento de amostragem do solo é descrita a seguir. foi utilizado Para traçar uma poligonal da área, utilizou-se o GPS Etrex Vista ${ }^{\circledR}$. De posse do polígono, procedeu-se a divisão da área em 80 células de manejo com quatro hectares cada uma. As células das bordaduras foram desconsideradas para fins de amostragem, seguindo uma diagonal com 12 pontos para compor a amostra representativa, dentro de cada uma das 80 células. As coordenadas desses pontos foram obtidas e arquivadas (MonteZANo et al., 2006).

A amostragem da folha indicadora foi realizada entre os dias 24/1 e 28/1/2004 nas coordenadas das subamostras do solo. A localização dos pontos foi feita com o uso do GPS Etrex Vista ${ }^{\circledR}$. Foram coletadas três folhas por ponto de subamostragem, de plantas diferentes, totalizando 36 folhas por amostra composta. Colheu-se o terço médio da folha oposta e abaixo da espiga no período do aparecimento da inflorescência feminina (cabelo), descartando-se a nervura central (Malavolta et al., 1997).

O material vegetal (lâminas de folha) foi seco em estufa de circulação forçada de ar com temperatura ajustada em cerca de $65^{\circ} \mathrm{C}$ por um período de 48 horas. O material seco foi moído em moinho tipo Wiley, passando as amostras em peneira de 20 mesh. Para as determinações de macro e micronutrientes, a exceção de $\mathrm{N}$ e $\mathrm{B}$, o material vegetal foi submetido à digestão nítrico-perclórica conforme descrito em Malavolta et al. (1997). No extrato nítrico-perclórico, a concentração de $\mathrm{P}$ foi determinada por espectrofotometria do metavanadato + molibdato, a de $\mathrm{K}$ por fotometria de emissão de chama, as concentrações de $\mathrm{Ca}, \mathrm{Mg}, \mathrm{Cu}, \mathrm{Fe}, \mathrm{Mn}$ e $\mathrm{Zn}$ por espectrofotometria de absorção atômica e a de $S$ por turbidimetria do sulfato de bário. Para a determinação de $\mathrm{N}$, submeteu-se o material vegetal à digestão sulfúrica e posterior destilação do extrato pelo método micro-Kjeldahl. O extrato vegetal para determinação da concentração de B foi obtido pela dissolução das cinzas provenientes da incineração do material seco, com posterior determinação pelo método espectrofotométrico da azometina-H.

Os dados de produtividade do talhão foram obtidos no momento da colheita, por meio de colhedora equipada com Sistema de Posicionamento Global (GPS), sensor de fluxo de grãos por placa de impacto, sensor de umidade de grãos, sensor de velocidade de deslocamento da colhedora e sensor de controle de altura da plataforma. Essas informações foram gerenciadas pelo monitor de rendimento de grãos AgLEADER PFAdvantage ${ }^{\circledR}$, arquivando as leituras de produtividade, altitude e umidade de grãos a cada dois segundos, durante a colheita da cultura em toda a área.

Utilizou-se o Sistema de Informação Geográfica (SIG) para a visualização dos dados brutos de produtividade de grãos e altitude. A partir desses dados, fez-se a interpolação, pelo método do inverso do quadrado da distância. Para a obtenção dos dados médios de produtividade e altitude, para cada uma das 80 células de manejo, usou-se o mesmo Sistema. Os pontos georeferenciados das subamostras de folha e os mapas de dados brutos de produtividade e altitude foram sobrepostos. Em cada ponto de subamostragem, foram selecionados os dados de produtividade e altitude, contidos em um círculo com $10 \mathrm{~m}$ de raio e calculou-se a média. As médias de produtividade e altitude de cada subamostra serviram para obter as respectivas médias de cada uma das 80 células de manejo (SHiRATsUCHI e MACHADO, 2003). Os mapas de superfície e da distribuição espacial foram construídos com o emprego do software de visualização de dados espaciais Surfer for Windows (Golden SOFTWARE, 1997).

$\mathrm{Na}$ análise estatística dos resultados considerou-se o cálculo dos parâmetros estatísticos referentes às medidas de tendência central e variabilidade, para cada conjunto de valores. Foram calculados os coeficientes de assimetria e curtose, para verificar o tipo e o formato da curva de distribuição da concentração foliar de cada nutriente. A medida da correlação linear do coeficiente de Pearson serviu para determinar a relação entre as concentrações dos nutrientes na folha e as médias de produtividade do milho e altitude da área, em cada célula de manejo, a $5 \%$ de probabilidade, pelo teste $t$. O software Statistica for Windows Statsoft (1996) foi o pacote estatístico utilizado nas análises. 


\section{RESULTADOS E DISCUSSÃO}

\section{Variabilidade nas concentrações de macronutrientes}

A análise estatística descritiva, para as concentrações de macro e micronutrientes determinadas em tecido foliar de milho, está apresentada na tabela 1 .

Considerando a proximidade entre os valores da média e mediana como indicativo de uma distribuição normal, observa-se que os resultados para $\mathrm{P}$ e $\mathrm{Mg}$ atendem a esse critério, pois a diferença foi de $0,01 \mathrm{~g} \mathrm{~kg}^{-1}$. O coeficiente de assimetria foi próximo de zero, o que corrobora para satisfazer a condição de distribuição normal do $\mathrm{P}$ e $\mathrm{Mg}$. Alguns pesquisadores, ao invés de utilizarem tabelas com limites de aceitabilidade para valores de assimetria com nível de significância, como a tabela de Jones (1969), preferem fixar um valor de aceitabilidade para a assimetria, como PAz et al. (1996), que aceitaram a hipótese de normalidade quando os valores de assimetria distanciaram-se de zero até no máximo um. Dentre os micronutrientes, $\mathrm{Cu}$ e $\mathrm{Zn}$ revelam valor do coeficiente de assimetria que satisfaz a hipótese de normalidade segundo PAz et al. (1996). A diferença entre as duas medidas de tendência central dos dois nutrientes foi de 0,44 e $2,08 \mathrm{mg} \mathrm{kg}^{-1}$ respectivamente, indicando que a distribuição de freqüências tende à normalidade.

Tabela 1. Medidas estatísticas descritivas para as concentrações de macro e micronutrientes em folha diagnóstica de milho

\begin{tabular}{|c|c|c|c|c|c|c|c|}
\hline \multirow{3}{*}{ Atributo } & \multirow{3}{*}{ Média } & \multicolumn{3}{|c|}{ Medidas estatísticas descritivas } & \multirow{2}{*}{\multicolumn{3}{|c|}{ Coeficiente }} \\
\hline & & \multirow{2}{*}{ Mediana } & \multirow{2}{*}{ Desvio-padrão } & \multirow{2}{*}{ Variância } & & & \\
\hline & & & & & Variação & Assimetria & Curtose \\
\hline $\mathrm{N}\left(\mathrm{g} \mathrm{kg}^{-1}\right)$ & 31,00 & 30,63 & 1,65 & 2,72 & 5,32 & 1,76 & 4,23 \\
\hline$P\left(\mathrm{~g} \mathrm{~kg}^{-1}\right)$ & 2,43 & 2,44 & 0,19 & 0,04 & 7,89 & 0,63 & 1,24 \\
\hline $\mathrm{K}\left(\mathrm{g} \mathrm{kg}^{-1}\right)$ & 23,97 & 23,40 & 2,29 & 5,22 & 9,53 & 2,28 & 5,04 \\
\hline $\mathrm{Ca}\left(\mathrm{g} \mathrm{kg}^{-1}\right)$ & 5,07 & 4,90 & 0,73 & 0,53 & 14,38 & 2,12 & 4,63 \\
\hline $\operatorname{Mg}\left(\mathrm{g} \mathrm{kg}^{-1}\right)$ & 2,08 & 2,09 & 0,24 & 0,06 & 11,31 & 0,25 & 0,12 \\
\hline $\mathrm{S}\left(\mathrm{g} \mathrm{kg}^{-1}\right)$ & 2,07 & 2,02 & 0,25 & 0,06 & 11,87 & 4,64 & 26,32 \\
\hline $\mathrm{Cu}\left(\mathrm{mg} \mathrm{kg}^{-1}\right)$ & 8,04 & 7,60 & 2,33 & 5,41 & 28,95 & 0,45 & $-0,71$ \\
\hline $\mathrm{Fe}\left(\mathrm{mg} \mathrm{kg}^{-1}\right)$ & 114,37 & 106,77 & 31,59 & 997,99 & 27,62 & 1,23 & 1,18 \\
\hline $\operatorname{Mn}\left(\mathrm{mg} \mathrm{kg}^{-1}\right)$ & 30,92 & 30,28 & 4,09 & 16,74 & 13,23 & 1,05 & 0,93 \\
\hline $\mathrm{Zn}\left(\mathrm{mg} \mathrm{kg}^{-1}\right)$ & 40,65 & 38,57 & 8,87 & 78,66 & 21,82 & 0,67 & $-0,66$ \\
\hline
\end{tabular}

Os nutrientes com baixa variabilidade são N, $\mathrm{P}, \mathrm{K}$, S e Mg, segundo o critério proposto por WARRICK e NieLSEn, (1980). Aqueles com média variabilidade são $\mathrm{Ca}$, único entre os macronutrientes, e todos os micronutrientes considerados na análise foliar.

BERNDTSSON e BAHRI (1995) verificaram que os teores dos nutrientes no solo apresentaram maior variação que as concentrações dos nutrientes na planta. Os mesmos autores argumentaram que outros fatores, além da influência das propriedades químicas do solo, afetam significativamente a variabilidade química na planta, a exemplo de tipo de planta, propriedades genéticas e variáveis do solo (disponibilidade de água, concentração dos solutos, etc.). O mesmo resultado é verificado comparando-se os coeficientes de variação encontrados por MontezAno et al (2006) para os macronutrientes P, S$\mathrm{SO}_{4}{ }^{2-}, \mathrm{K}, \mathrm{Ca}$ e $\mathrm{Mg}$, e os micronutrientes $\mathrm{Cu}, \mathrm{Fe}, \mathrm{Mn}$ e Zn determinados em amostras de solo na mesma área de estudo. Em todos os coeficientes, a exceção do Fe, os valores foram maiores em relação aos coeficientes calculados a partir das concentrações dos nutrientes nas folhas, apresentados neste trabalho.

CAmelo et al. $(1993 ; 1994)$ verificaram que a variação do $\mathrm{P}$ na planta foi menor que no solo. Também comentaram sobre o elevado número de fatores que interferem na distribuição do $\mathrm{P}$ absorvido pelas plantas, os quais Malavolta et al. (1997) dividem em fatores externos (disponibilidade, aeração, temperatura, o próprio elemento, interação com outros íons, pH, micorrizas e rizosfera) e internos (potencialidade genética, estado iônico interno, nível de carboidratos, intensidade transpiratória, morfologia da raízes). Entretanto, como a planta explora um volume de solo maior que o representado pela amostra, ela diluiria, então, a variabilidade do solo, compensando suas diferenças pontuais (CAMELO et al., 1993; 1994). Outro comentário importante referese aos limites de concentração dos nutrientes nas plantas, mais estreitos que as faixas de teor dos 
elementos no solo. A planta possui uma composição química mais definida, o que influencia em menor dispersão nas observações e na distribuição de freqüências, não se afastando muito da distribuição normal (CAMELO et al., 1993; 1994).

\section{Variabilidade da produtividade do milho}

A análise exploratória dos dados médios de produtividade e altitude está apresentada nos mapas de superfície (Figura 1) e de distribuição espacial dos dados para cada célula de manejo (Figura 2). Observase que na parte central da área as produtividades foram maiores, acima de $8,0 \mathrm{t} \mathrm{ha}^{-1}$. As menores produtividades ocorreram próximo aos limites da área. A amplitude foi de 1,9 $\mathrm{tha}^{-1}$, demonstrando diferenças significativas de produção, o que resultará em diferenças também significativas de renda para cada célula analisada. O relevo da área foi classificado como suave ondulado, como se verifica no mapa de superfície da altitude da área (Figura 1).
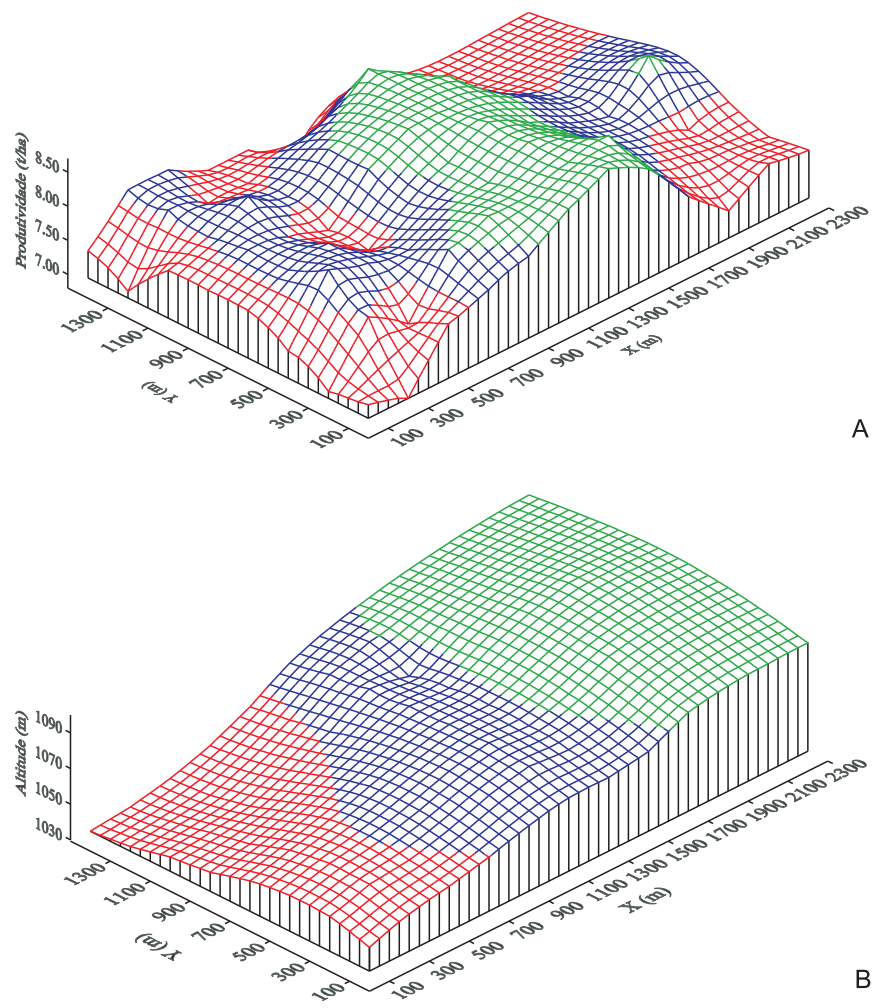

Figura 1. Mapas de superfície para produtividade de grãos de milho (a) e altitude em relação ao nível do mar (b).

A produtividade das culturas é variável devido à heterogeneidade das propriedades físicas, químicas e biológicas do solo (BRESLER e LAUFER, 1988) e essas por sua vez, interferem, como fatores externos, na absorção dos nutrientes pelas plantas, provocando desenvolvimento irregular da cultura dentro de uma área de produção (TSEGAYE e HiLl, 1996). É importante, portanto, conhecer a variabilidade dos nutrientes no tecido vegetal antes de aplicar adubo em resposta a esta variação.
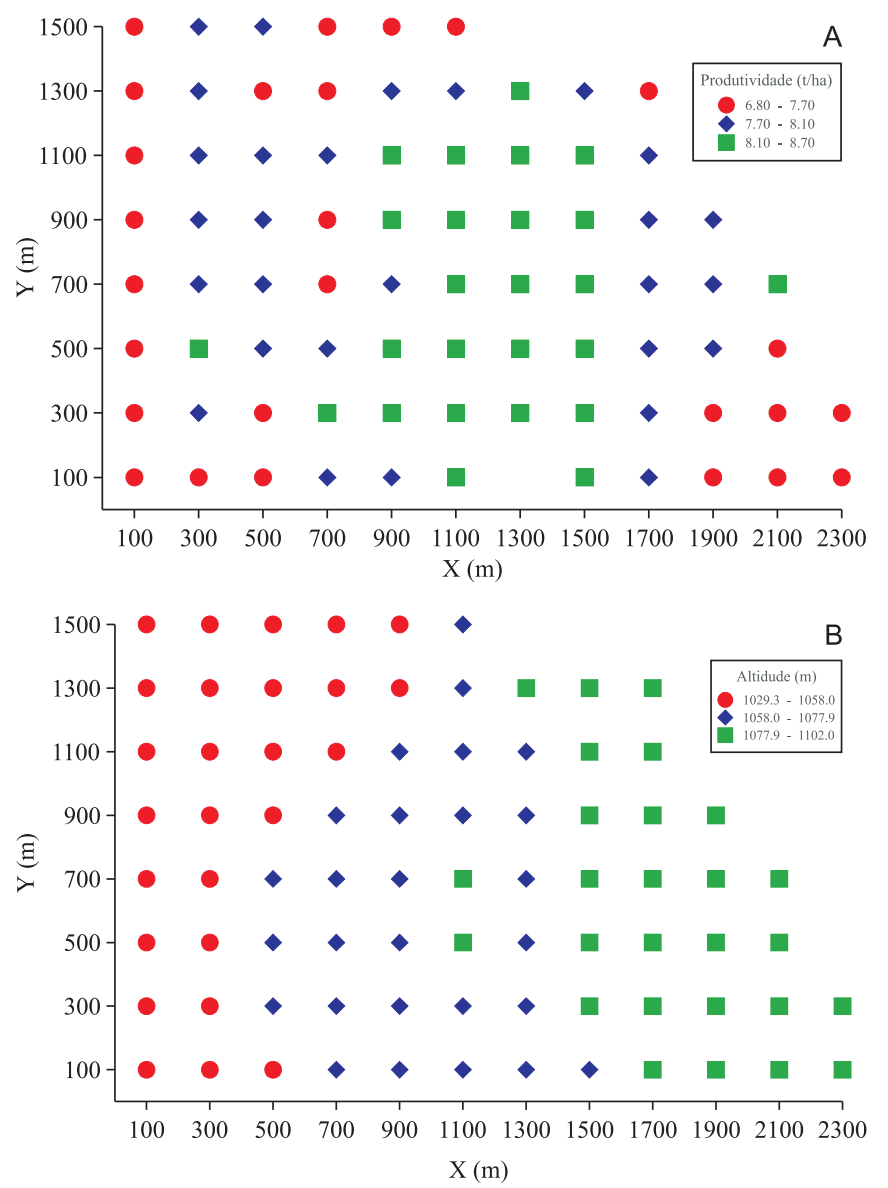

Figura 2. Distribuição espacial de produtividade de grãos de milho (a) e altitude em relação ao nível do mar (b).

\section{Correlações de macro e micronutrientes com a produtividade do milho}

Aproximadamente $50 \%$ dos coeficientes de correlação linear entre os elementos de nutrição mineral do milho foram significativos pelo teste $\mathrm{t}$ com 95\% de confiabilidade (Tabela 2 ).

$\mathrm{O} \mathrm{N}$ correlacionou de forma positiva com os macronutrientes $\mathrm{P}, \mathrm{K}, \mathrm{Ca}$ e $\mathrm{S}$, e de forma negativa com o Mg. Para $\mathrm{P}, \mathrm{K}, \mathrm{Ca}$ e $\mathrm{S}$ os resultados demonstram que as plantas bem nutridas em $\mathrm{N}$ são mais eficientes em absorver outros elementos devido ao maior crescimento do sistema radicular. Este raciocínio, porém, não se aplica ao caso do $\mathrm{Mg}$. Altas concentrações de $\mathrm{Ca}^{2+}$, e sobretudo de $\mathrm{K}^{+}$no meio, podem inibir competitivamente a absorção de $\mathrm{Mg}^{2+}$, causando, às vezes, a deficiência desse nutriente (MALAVOLTA et al., 1997). 
O P correlacionou positivamente com $\mathrm{K}, \mathrm{Ca}$, $\mathrm{S}$ e o Fe e negativamente com o $\mathrm{Zn}$. Segue neste caso o mesmo citado para o N, ou seja, quanto melhor nutrida a planta em $P$, maior o crescimento do sistema radicular, permitindo que a planta explore volume maior de solo.

$\mathrm{O} \mathrm{K}$ correlacionou positivamente com o Ca e o Fe e negativamente com o $\mathrm{Mn}$ e o $\mathrm{Zn}$. O efeito sinérgico entre $\mathrm{K}$ e Ca foi demonstrado pela maior correlação entre estes. Malavolta et al. (1997) comprovaram que o íon $\mathrm{Ca}^{2+}$, em concentrações não muito elevadas, aumenta a absorção de cátions e de ânions por seu papel na manutenção da integridade funcional da plasmalema. Segundo Oliveira (2004), as concentrações de Ca no tecido foliar estão contidas dentro da faixa considerada adequada para o milho $\left(2,5\right.$ a $\left.10 \mathrm{~g} \mathrm{~kg}^{-1}\right)$.

Se por um lado, a absorção do Fe é influenciada por outros cátions como $\mathrm{K}, \mathrm{Ca}$ e $\mathrm{Mg}$, por outro lado, o $\mathrm{Cu}$, o $\mathrm{Zn}$ e o Mn podem induzir a deficiência de $\mathrm{Fe}$, presumivelmente por inibição competitiva (Malavolta et al., 1997). Assim, houve correlação significativa positiva do $\mathrm{Fe}$ com os cátions K e Ca. Houve também correlação entre o Fe e o P.

O Mn correlacionou negativamente com o K, $\mathrm{Mg}$ e o Fe. Houve correlação positiva do Mn com o $\mathrm{Cu}$ e o $\mathrm{Zn}$. O Mn tem propriedades químicas semelhantes às dos metais alcalinos terrosos, como Ca e o $\mathrm{Mg}$, e de metais pesados, Fe e $\mathrm{Zn}$, por exemplo, e, por isso, esses cátions podem inibir sua absorção e transporte. Por sua vez, o Mn inibe a absorção daqueles mencionados acima, principalmente do $\mathrm{Fe}$ (Malavolta et al., 1997).

O Zn correlacionou negativamente tanto com o P quanto com o K, Ca e o Fe. Segundo Malavolta et al. (1997) há efeito de inibição competitiva e não competitiva do $\mathrm{Zn}^{2+}$ com o $\mathrm{Ca}^{2+}$ e $\mathrm{H}_{2} \mathrm{PO}_{4}{ }^{-}$ respectivamente. Houve correlação positiva do $\mathrm{Zn}$ com os micronutrientes $\mathrm{Cu}$ e $\mathrm{Mn}$.

Não foram significativos os coeficientes de correlação entre a maioria dos atributos de nutrição mineral e os dados de produtividade média para cada célula de manejo (Tabela 2). Destacam-se, porém, as correlações negativas entre a produtividade média de milho com os micronutrientes $\mathrm{Cu}, \mathrm{Mn}$ e $\mathrm{Zn}$, as quais foram significativas e estão diretamente ligadas ao fornecimento anual desses nutrientes nas adubações. Como as determinações dos valores de $\mathrm{pH}$ do solo revelaram que a acidez está contida na faixa de interpretação agronômica considerada de média acidez, pode-se inferir uma maior disponibilidade dos micronutrientes catiônicos.

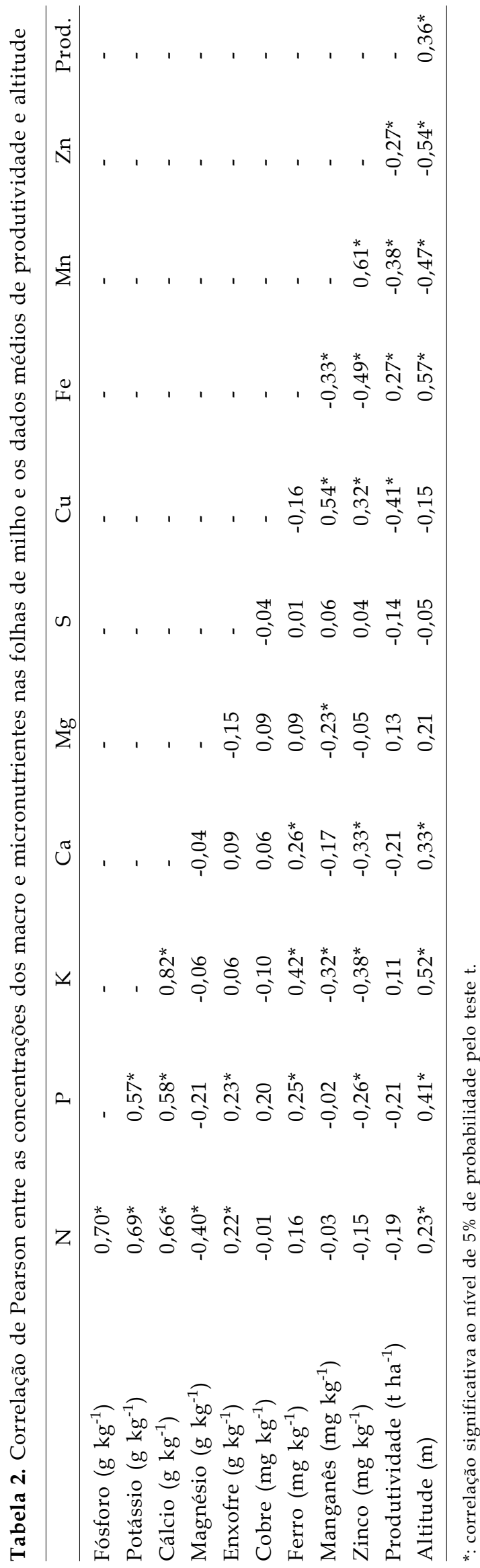

Bragantia, Campinas, v.67, n.4, p.969-976, 2008 
Aliado ao fornecimento das adubações anuais, permite-se deduzir sobre provável consumo de luxo desses micronutrientes. Segundo a tabela de concentrações adequadas de nutrientes para as principais culturas no Cerrado (Oliveira, 2004), os teores de Mn e Zn para todas as amostras estão dentro da faixa de concentração considerada adequada para estes dois micronutrientes na cultura do milho. $\mathrm{Na}$ maioria das amostras, verificaram-se concentrações adequadas de $\mathrm{Cu}$, segundo a referência acima citada; em $21,25 \%$ das amostras o teor de $\mathrm{Cu}$ ficou abaixo do limite inferior da faixa considerada adequada. Logicamente, deve-se considerar que outros fatores de produção estiveram envolvidos no desempenho da cultura no campo.

A altitude proporcionou correlação positiva com a produtividade de milho (Tabela 2). Uma possível explicação, refere-se ao fato de que a declividade influencia o fluxo da água no solo, diretamente associado à produtividade das culturas em áreas de sequeiro, em especial na ocorrência de veranicos. Como a determinação das variáveis associadas à água não era objeto deste estudo, não foi possível avaliar seu efeito sobre a produtividade. Nas concentrações de macro e micronutrientes, à exceção de $\mathrm{Mg}$, $\mathrm{S}$ e $\mathrm{Cu}$, houve correlação significativa com a altitude. Os nutrientes tiveram associação mais direta com a altitude do que com a produtividade do milho, a exceção do $\mathrm{S}$ e do $\mathrm{Cu}$.

\section{CONCLUSÕES}

1. Nas concentrações dos macronutrientes $\mathrm{N}$, $\mathrm{P}, \mathrm{K}, \mathrm{Mg}$ e S, na folha indicadora das plantas de milho cultivado em área manejada homogeneamente ocorreu baixa variabilidade, à exceção do $\mathrm{Ca}$, com média. As concentrações dos micronutrientes $\mathrm{Cu}, \mathrm{Fe}, \mathrm{Mn}$ e $\mathrm{Zn}$ tiveram média variabilidade.

2. A variabilidade da produtividade de milho demonstrou diferenças de produção para cada célula analisada que devem ser consideradas no manejo dos próximos cultivos na área.

3. Nas concentrações de $\mathrm{Cu}, \mathrm{Mn}$ e $\mathrm{Zn}$ a correlação foi negativa com a produtividade de milho, e em $\mathrm{Fe}$, houve correlação positiva. Os macronutrientes $\mathrm{N}, \mathrm{P}, \mathrm{K}, \mathrm{Ca}, \mathrm{Mg}$ e S não tiveram correlação significativa com a produtividade de milho.

\section{REFERÊNCIAS}

BERNDTSSON, R.; BAHRI, A. Field variability of element concentrations in wheat and soil. Soil Science, Madison, v.159, n.5, p.311-320, 1995.
BRESLER, E.; LAUFER, A. Statistical inferences of soil operties and crop yield as spatial random functions. Soil Science Society American Journal, Madison, v.52, p.12341244, 1988.

BÜLL, L.T. Nutrição mineral do milho. In: BÜLL, L.T.; CANTARELLA, H. (Ed.). Cultura do milho: fatores que afetam a produtividade. Piracicaba: Potafos, p.63-145, 1993.

CAMELO, L.G.L.; SIERRA, J.; FUMAGALLI, C.; MIGUEZ, S.R. Variabilidade espacial de fosforo en suelo y planta en um Argiudol Típico bajo cultivo de maiz. Revista de la Facultad de Agronomia, v.14, p.1-18, 1993/94.

EMPRESA BRASILEIRA DE PESQUISA AGROPECUÁRIA. Sistema Brasileiro de Classificação de Solos. Brasília: CNPS, 1999. 412p.

GOLDEN SOFTWARE. Surfer for windows. v.6,04. Colorado: Golden, 1997.

JONES, T.A. Skewness and Kurtosis as criteria of normality in observed frequency distributions. Journal of Sedimentary Petrology, Tulsa, v. 39, p.1622-1627, 1969.

MALAVOLTA, E.; VITTI, G.C.; OLIVEIRA, S.A. Avaliação do estado nutricional das plantas. 2.ed. Piracicaba: Potafos, 1997.319p.

MONTEZANO, Z.F.; CORAZZA, E.J.; MURAOKA, T. Variabilidade espacial da fertilidade do solo em área cultivada e manejada homogeneamente. Revista Brasileira de Ciência do Solo, Viçosa, v.30, p.839-847, 2006.

OLIVEIRA, S.A. Análise foliar. In: SOUSA, D.M.G.; LOBATO, E. (Ed.). Cerrado: correção do solo e adubação. 2.ed. Brasília: EMBRAPA, 2004. p.245-256.

PAZ, A.; TABOADA, M.T.; GÓMEZ, M.J. Spatial variability in topsoil micronutrient contents in a one-hectare cropland plot. Communications in Soil Science and Plant Analysis, New York, v.27, n.3/4, p.479-503, 1996.

SALVIANO, A.A.C.; VIEIRA, S.R.; SPAROVEK, G. Variabilidade espacial de atributos de solo e de Crotalaria juncea L. em área severamente erodida. Revista Brasileira de Ciência do Solo, Viçosa, v.22, p.115-122, 1998.

SHIRATSUCHI, L.S.; MACHADO, A.L.T. Variação do espaçamento entre faixas de colheita na geração de mapas de produtividade. Planaltina-DF: Embrapa Cerrados, 2003. 25p. (Boletim de Pesquisa e Desenvolvimento, 90)

SILVEIRA, P.M.; ZIMMERMANN, F.J.P.; SILVA, S.C.; CUNHA, A.A.. Amostragem e variabilidade espacial de características químicas de um Latossolo submetido a diferentes sistemas de preparo. Pesquisa Agropecuária Brasileira, Brasília, v.35, p.2057-2064, 2000.

SOUZA, L.S. Variabilidade espacial do solo em sistemas de manejo. 1992. 162f. Tese (Doutorado) - Universidade Federal do Rio Grande do Sul, Porto Alegre.

STATSOFT. Statistica for windows. v.6.0. Tulsa: Statsoft, 1996. 
TRANGMAR, B.B.; YOST, R.S.; UEARA, G. Applications of geoestatistics to spatial studies of soil properties. Soil Science Society of America Journal, Madison, v.51, p.668$674,1987$.

TSEGAYE, T.; HILL, R.L. Wheel traffic placement effects on corn response under no-tillage and conventional tillage. Journal Production Agriculture, Madison, v.9, p.95-101, 1996.

WARRICK, A.W.; NIELSEN, D.R. Spatial variability of soil physical properties in the field. In: HILLEL, D. (Ed.). Applications of soil physics. New York: Academic Press, 1980. cap.13, p.319-344. 